\title{
APLIKASI MONITORING PROSES MARKETING DIVISI PENERIMAAN MAHASISWA BARU (PMB) (STUDI KASUS : AMIK TRI DHARMA PEKANBARU)
}

\author{
Syahrul \\ Akademi Manajemen Informatika \& Komputer (AMIK) Tri Dharma Pekanbaru \\ Jalan Jendral Sudirman No. 68, Pekanbaru - Riau \\ Email: aun67@gmail.com
}

\begin{abstract}
ABSTRAK
Monitoring adalah proses rutin pengumpulan data dan pengukuran kemajuan atas objektif program. Memantau perubahan, yang focus pada proses dan keluaran. Sedangkan evaluasi adalah penggunaan metode penelitian social untuk secara sistematis menginvestigasi efektifitas kinerja dari suatu perusahaan. Teknologi telah mengubah paradigma kehidupan manusia menjadi lebih mudah sehingga segala hal yang kita kerjakan bisa lebih efisien dan efektif. Begitu juga dengan AMIK Tri Dharma Pekanbaru yang memerlukan sebuah aplikasi sistem informasi untuk memonitoring dan mengevaluasi kinerja pegawainya khusunya pada divisi penerimaan mahasiswa baru (PMB). Hasil Dari rancangan aplikasi Monitoring Proses Marketing yang dibangun ini adalah diharapkan akan memberikan kemudahan bagi koordinator/pimpinan divisi penerimaan mahasiswa baru (PMB) dalam mengontrol atau memantau setiap pegawai yang melakukan visit dalam proses marketing secara langsung.
\end{abstract}

Kata Kunci : Aplikasi, Monitoring, Marketing, AMIK Tri Dharma Pekanbaru

\section{PENDAHULUAN}

Dalam era globalisasi, kelengkapan, keakuratan dan kecepatan informasi menjadi suatu yang sangat penting. Informasi menjadi sangat berharga apabilah disampaikan secara lengkap dan akurat dalam waktu yang cepat. Dengan semakin lengkap, akurat dan cepatnya informasi yang diterima, maka pengambilan keputusan bisa berlangsung dengan cepat. Karena informasi merupakan salah satu variabel penting dalam proses pengambilan keputusan.

Di AMIK Tri Dharma Pekanbaru, keakuratan dan keterlambatan informasi menjadi suatu hambatan yang besar bagi koordinator atau pimpinan Divisi Penerimaan Mahasiswa Baru (PMB) Proses Marketing dalam memantau atau memonitoring setiap kegiatan marketing yang dilakukan oleh setiap hari. Seringkali setiap kegiatan proses marketing yang terjadi, koordinator tidak dapat mengetahui atau menerima informasi tentang setiap kegiatan proses marketing yang terjadi secara langsung.

Wilayah kerja bagian marketing meliputi seluruh sekolah yang ada di provinsi Riau. Mengingat luasnya wilayah kerja marketing yang menjadi tanggung jawab mereka, maka hal tersebut dapat menimbulkan masalah. Pertama, marketing tidak dapat melakukan pengecekan data sekolah baik yang sudah dikunjungi maupun yang belum dikarenakan belum adanya sebuah sistem yang mengolah data tersebut. Sehingga marketing harus mengingat kembali dan menanyakan ke bagian admin yang berada dikantor melalui telephon seluler, hal tersebut membutuhkan waktu yang relatif lama.

Kedua, selain permasalahan diatas, permasalahan lain terkait dengan proses marketing dalam melaksanakan tugasnya yaitu bagian pimpinan atau koordinator tidak dapat memonitoring baik dalam hal visiting (kunjungan) kesekolah, kemudian data dari setiap sekolah serta informasi mengenai visit yang dilakukan marketing setiap harinya. Selain itu, proses monitoring tersebut digunakan untuk memonitoring sekolah mana yang memiliki potensi pembiayaan tertinggi. Pencapaian target menjadi tolak ukur penilaian dalam pemberian reward kepada marketing, apakah sudah mencapai target yang sudah ditentukan oleh perusahaan atau belum.

Adapun permasalahan yang muncul di dalam monitoring proses marketing di Divisi Business Service Pekanbaru pada saat ini adalah : 


\section{INFORM T I K}

\section{Jurnal Informatika, Manajemen dan Komputer, Vol. 10 No. 2 , Desember 2018}

eISSN : 2580-3042

pISSN : 1979-0694

1. Sistem Informasi Monitoring Proses Marketing AMIK Tri Dharma Pekanbaru Divisi Penerimaan Mahasiswa Baru (PMB) belum mengoptimalkan pemanfaatan Teknologi Informasi.

2. Pencatatan, pemantauan atau pengawasan setiap kegiatan marketing tidak dapat dilakukan secara cepat dan akurat semua masih dilakukan secara manual.

3. Belum memiliki dan menggunakan rancangan database elektronik untuk kumpulan datanya sehingga mudah terjadi redudansi data dan data tidak konsisten.

4. Setiap hasil proses marketing tidak terdapat laporan yang mendukung secara akurat.

5. Pegawai yang melakukan visit (kunjungan) ke sekolah tidak bisa dipantau secara langsung sehingga tidak diketahui setiap melakukan visit.

Agar memperoleh penelitian yang maksimal dan terfokus maka, peneliti membatasi penelitian pada analisis dan perancangan sistem informasi monitoring proses marketing sebagai berikut :

1. Perancangan aplikasi sistem informasi ini untuk mengawasi atau memonitoring setiap kegiatan dari proses marketing yang dilakukan setiap pegawai.

2. Meningkatkan kinerja pegawai dalam melakukan proses marketing ke calon mahasiswa/i baru.

3. Menghasilkan suatu laporan dari hasil visit (kunjungan) ke sekolah yang dilakukan sebagai bukti pertanggung jawaban.

\section{a. Tujuan Penelitian}

Menghasilkan aplikasi sistem informasi monitoring dan evaluasi proses marketing divisi Penerimaan Mahasiswa Baru (PMB) yang sesuai dengan kebutuhan di AMIK Tri Dharma Pekanbaru.

\section{b. Aplikasi}

Menurut (Nazruddin Safaat, 2012) Perangkat lunak aplikasi adalah suatu subkelas perangkat lunak komputer yang memanfaatkan kemampuan komputer langsung untuk melakukan suatu tugas yang diinginkan pengguna. Biasanya dibandingkan dengan perangkat lunak sistem yang mengintegrasikan berbagai kemampuan komputer, tapi tidak secara langsung menerapkan kemampuan tersebut untuk mengerjakan suatu tugas yang menguntungkan pengguna. Contoh utama perangkat lunak aplikasi adalah pengolah kata, lembar kerja, dan pemutar media. Beberapa aplikasi yang digabung bersama menjadi suatu paket kadang disebut sebagai suatu paket atau suite aplikasi (application suite). Contohnya adalah Microsoft Office dan Open Office.org, yang menggabungkan suatu aplikasi pengolah kata, lembar kerja, serta beberapa aplikasi lainnya. Aplikasi-aplikasi dalam suatu paket biasanya memiliki antarmuka pengguna yang memiliki kesamaan sehingga memudahkan pengguna untuk mempelajari dan menggunakan setiap aplikasi. Sering kali, aplikasi ini memiliki kemampuan untuk saling berinteraksi satu sama lain sehingga menguntungkan pengguna. Contohnya, suatu lembar kerja dapat dibenamkan dalam suatu dokumen pengolah kata walaupun dibuat pada aplikasi lembar kerja yang terpisah.

\section{c. Monitoring}

Monitoring, dalam bahasa Indonesia dikenal dengan istilah pemantauan. Monitoring merupakan sebuah kegiatan untuk menjamin akan tercapainya semua tujuan organisasi dan manajemen (Handoko, 1995). Dalam kesempatan lain, monitoring juga didefinisikan sebagai langkah untuk mengkaji apakah kegiatan yang dilaksanakan telah sesuai dengan rencana, mengidentifikasi masalah yang timbul agar langsung dapat diatasi, melakukan penilaian apakah pola kerja dan manajemen yang digunakan sudah tepat untuk mencapai tujuan, mengetahui kaitan antara kegiatan dengan tujuan untuk memperoleh ukuran kemajuan (Sutabri, 2012). Dengan kata lain, monitoring merupakan salah satu proses didalam kegiatan organisasi yang sangat penting yang dapat menentukan terlaksana atau tidaknya sebuah tujuan organisasi. Tujuan dilakukannya monitoring adalah untuk memastikan agar tugas pokok organisasi dapat berjalan sesuai dengan rencana yang telah ditentukan (Mega \& Aviana, 2012).

\section{d. Marketing}

Menurut (Stanton, 2013), pemasaran adalah suatu sistem dari kegiatan bisnis yang dirancang untuk merencanakan, menentukan harga, mempromosikan dan mendistribusikan produk yang dapat memuaskan keinginan dalam mencapai tujuan perusahaan. Menurut (Kotler Philip, 2014) "Marketing as the process by which companies create value for customers and build strong customer relationships in order to capture value from customers in return", artinya menyatakan bahwa pemasaran sebagai proses dimana perusahaan menciptakan nilai bagi pelanggan dan membangun hubungan pelanggan yang kuat untuk menangkap nilai dari pelanggan sebagai imbalan. 


\section{INFORM T I K A}

\section{Jurnal Informatika, Manajemen dan Komputer, Vol. 10 No. 2 , Desember 2018}

eISSN : 2580-3042

pISSN : 1979-0694

Menurut (Stanton, 2013) pemasaran adalah proses manajemen yang berupaya memaksimumkan laba (retutns) bagipemegang saham dengan jalan menjalin relasi dengan pelanggan utama (valued customers) dan menciptakan keunggulan kompetitif. Menurut Melydrum dalam Sudaryono (2016:41), pemasaran adalah proses bisnis yang berusaha menyelaraskan antara sumber daya manusia, finansial dan fisik organisasi dengan kebutuhan dan keinginan para pelanggan dalam konteks strategi kompetitif. Jadi dapat disimpulkan, pemasaran adalah suatu kegiatan perekonomian yang dilakukan untuk memenuhi kebutuhan dan keinginan konsumen dengan produk yang telah ditawarkan oleh perusahaan.

\section{METODOLOGI PENELITIAN}

Untuk membantu dalam penyusunan metode penelitian ini, maka perlu adanya susunan kerangka kerja yang jelas tahapan-tahapannya. Kerangka kerja ini merupakan langkah-langkah yang akan dilakukan dalam penyelesaian masalah yang ada di AMIK Tri Dharma Pekanbaru, berikut adalah kerangka kerja:

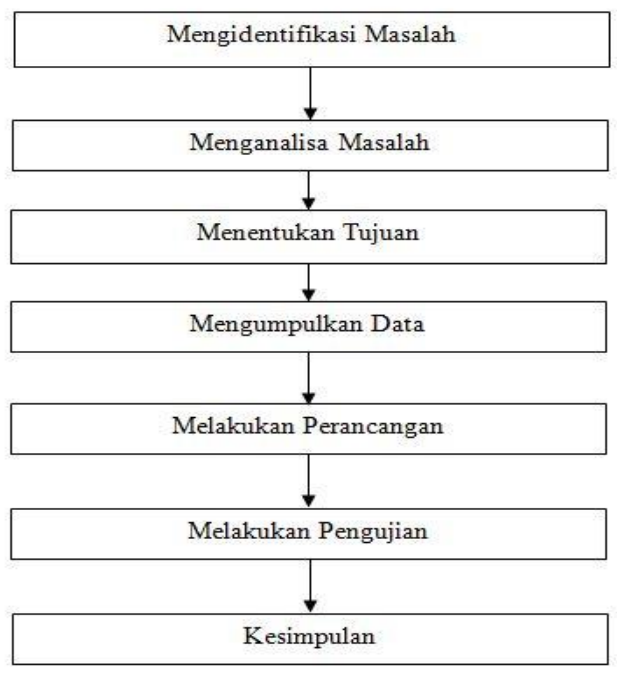

Gambar 1. Kerangka Kerja

Berdasarkan gambar diatas, dapat dijabarkan urutan-urutan langkah kerja sebagai berikut:

1. Mengidentifikasi Masalah

Permasalahan utama dalam penelitian ini adalah sistem yang ada saat ini masih belum bisa memberikan informasi yang akurat untuk monitoring proses marketing pada divisi penerimaan mahasiswa baru (PMB).

\section{Menganalisa Masalah}

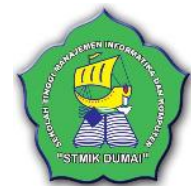

Penganalisaan terhadap masalah yang telah diidentifikasikan perlu dilakukan, apakah data mengenai proses monitoring marketing pada divisi penerimaan mahasiwa baru dapat dianalisa dengan bantuan web. Dengan tujuan untuk mempermudah menyampaikan informasi kepada korrdinator/pimpinan perihal informasi hasil visit (kunjungan) ke sekolah yang dilakukan sebagai bukti pertanggung jawaban tersebut.

\section{Menentukan Tujuan}

Tujuan utama dalam penelitian ini adalah untuk memberikan informasi monitoring dan evaluasi proses marketing divisi Penerimaan Mahasiswa Baru (PMB) yang sesuai dengan kebutuhan di AMIK Tri Dharma Pekanbaru.

\section{Mengumpulkan Data}

Pengumpulan data mengenai data monitoring dan evaluasi proses marketing pada divisi penerimaan mahasiswa baru diperoleh dengan cara melakukan pengamatan langsung ke AMIK Tri Dharma Pekanbaru.

5. Melakukan Perancangan

Adapun penjelasan lebih rinci mengenai perancangan aplikasi sistem informasi monitoring dan evaluasi peoses marketing pada divisi penerimaan mahasiswa baru digambarkan menggunakan Unified Modelling Language (UML).

\section{Melakukan Pengujian}

Melakukan pengujian merupakan proses terakhir sebelum mendapatkan pengetahuan baru dari data yang ada.

7. Kesimpulan

Setelah dilakukan pengujian, langkah berikutnya adalah penentuan/pengambilan keputusan berdasarkan hasil yang telah dilakukan sebelumnya, sehingga akan muncul hasil program yang prioritas atau yang tidak prioritas.

\section{HASIL DAN PEMBAHASAN}

Dengan adanya aplikasi ini marketing dapat memproses hasil visit sekolah, serta dapat melihat jumlah calon mahasiswa baru dan jumlah insentif yang akan diterima. Selain itu pimpinan atau koordinator juga dapat melihat jumlah target dan jumlah insentif yang akan diberikan dengan menggunakan aplikasi tersebut. Berikut desain aplikasi dan hasil implementasi dari rancangan aplikasi monitoring proses marketing pada divisi penerimaan mahasiswa baru (PMB) yang ada di AMIK Tri Dharma Pekanbaru. 
I N F ORM A T I R

Jurnal Informatika, Manajemen dan Komputer, Vol. 10 No. 2 , Desember 2018

eISSN : 2580-3042

pISSN : 1979-0694

\section{a. Desain Menu Utama}

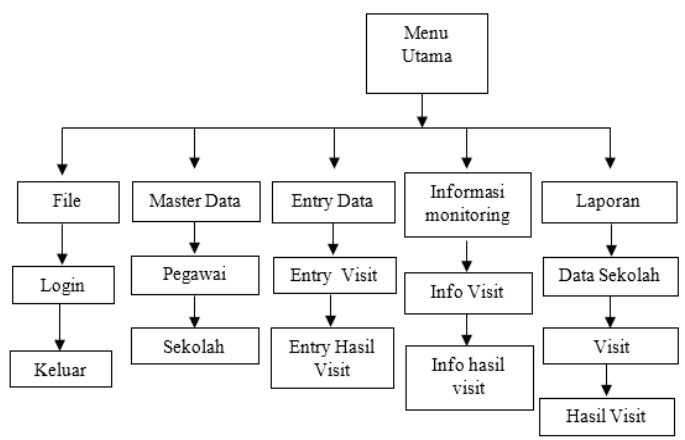

Gambar 2. Desain Menu Utama

\section{b. Desain Output Hasil Visit Sekolah}

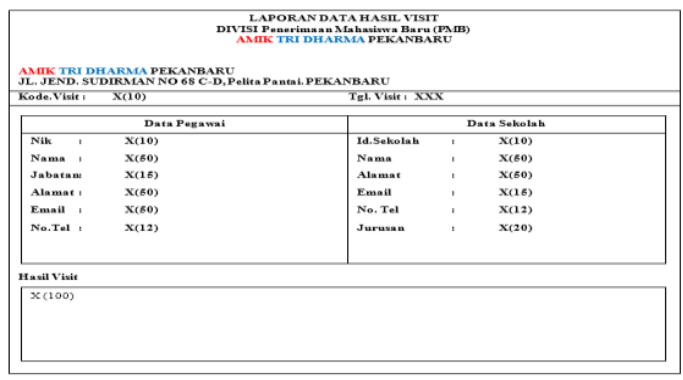

Gambar 3. Desain Ouput Hasil Visit Sekolah

Gambar diatas adalah rancangan output hasil visit sekolah yang diperoleh divisi marketing untuk di laporkan ke koordinator atau pimpinan.

\section{c. Desain Form Login}

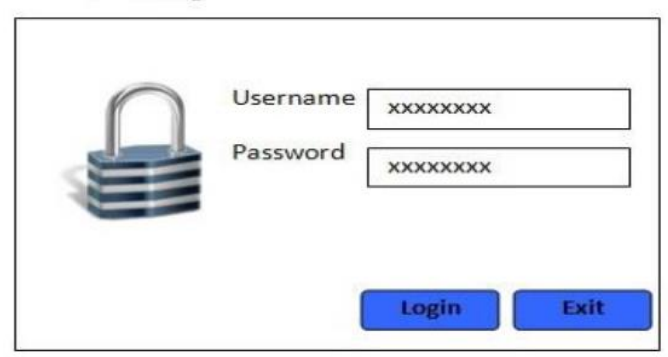

Gambar 4. Form Login

Form login adalah form pertama yang tampil ketika aplikasi monitoring ini dijalankan. Form ini digunakan untuk mengamankan program dari para pengguna yang tidak bertanggung jawab, hanya orang yang mempunyai hak akseslah yang bisa menggunakan atau membuka program ini.

\section{d. Desain Input Data Pegawai}

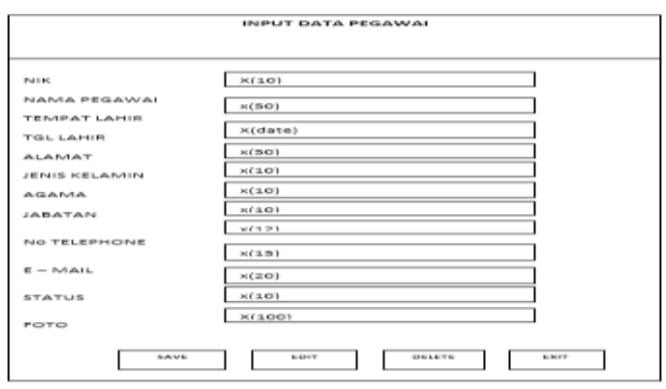

Gambar 5. Desain Input Pegawai

Gambar 5 menerangkan bahwa rancangan pengolahan data pegawai pada dvisi marketing penerimaan mahasiswa baru dengan memiliki fungsi input, pencarian, update dan hapus data pegawai.

\section{e. Hasil Implementasi \\ Menu Utama}

Di dalam tampilan menu utama digambarkan pilihan pilihan apa saja yang dibutuhkan dalam sistem tersebut sesuai dengan hak akses yang diberikan.

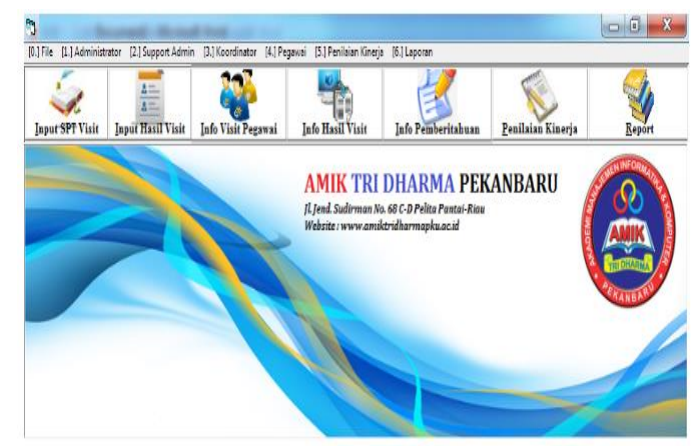

Gambar 6. Desain Menu Utama

\section{Entri Data Pegawai}

Fungsi form ini berfungsi sebagai pengolahan data pegawai mulai dari penginputan data, pencarian, dan menghapus data pegawai.

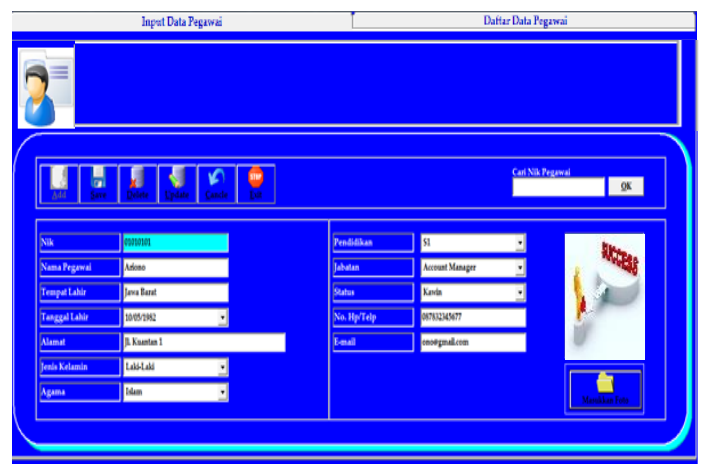

Gambar 7. Desain input Data Pegawai 
INFORM A IK A

Jurnal Informatika, Manajemen dan Komputer, Vol. 10 No. 2 , Desember 2018

eISSN : 2580-3042

pISSN : 1979-0694

\section{Entri Data Sekolah}

Fungsi dari form entri data sekolah adalah untuk mengetahui data sekolah yang akan dikunjungi dan untuk mencari data sekolah yang sudah di visit oleh marketing.

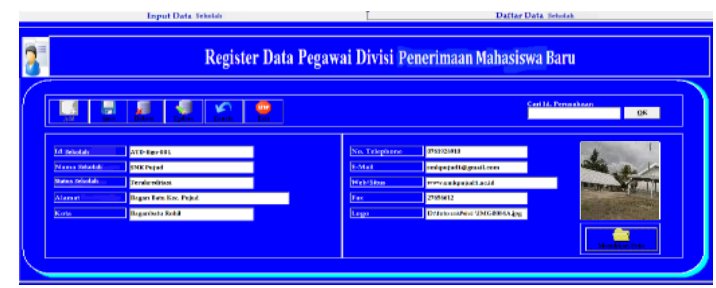

Gambar 8. Desain input Data Sekolah

\section{Penilaian Kinerja Pegawai}

Form ini digunakan untuk input data penilaian terhadap pegawai marketing, dimana nantinya pimpinan bisa memonitoring kinerja dari setiap pegawai di divisi marketing.

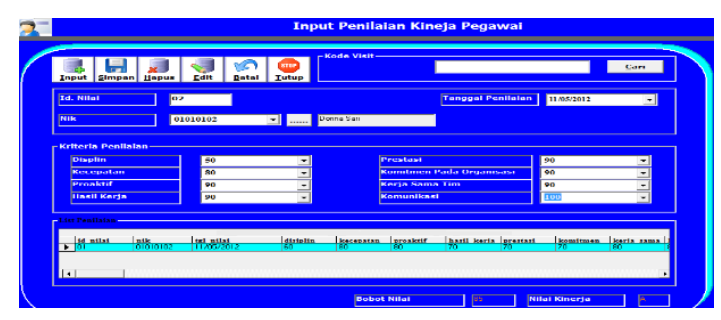

Gambar 9. Desain Penilaian Kinerja Pegawai

\section{Hasil Visit Sekolah}

Form ini berfungsi sebagai hasil proses penginputan data visit marketing yang akan dikunjungi dan dilaporkan ke koordinator/ pimpinan.

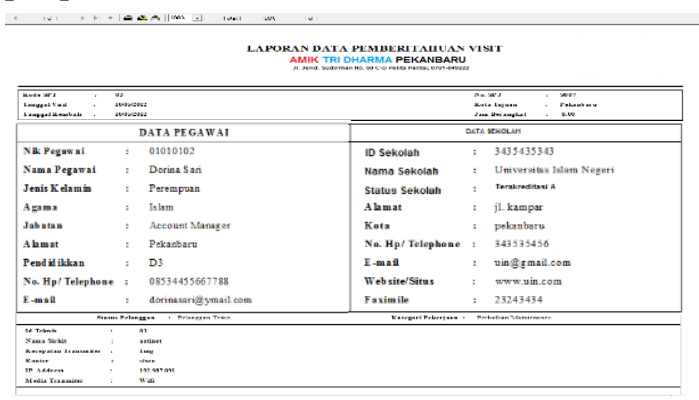

Gambar 10. Hasil Penilaian Kinerja Pegawai

\section{KESIMPULAN}

Setelah melakukan penelitian pada Kampus AMIK Tri Dharma Pekanbaru bagian Divisi Penerimaan Mahasiswa Baru (PMB) yang berada di jalan Jend. Sudirman No. 68 C-D Pelita Pantai Pekanbaru Riau dan menyusunnya menjadi penelitian, maka penulis dapat mengambil kesimpulan sebagai berikut :

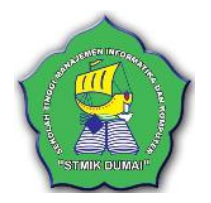

1. Penggunaan Sistem Informasi Monitoring Proses Marketing akan memberikan kemudahan bagi koordinator/pimpinan Divisi Penerimaan Mahasiswa Baru (PMB) dalam mengontrol atau memantau setiap pegawai yang melakukan visit dalam proses marketing secara langsung.

2. Dapat membantu koordinator/pimpinan untuk mengetahui kinerja pegawai dalam proses marketing yang dilakukannya serta memberikan arahan/masukan kepada pegawai.

3. Dapat menyampaikan informasi-informasi yang sebelumnya bersifat manual ke sistem yang telah terkomputerisasi.

4. Penggunaan sistem baru ini akan menghasilkan output yang lebih baik sehingga dapat diperoleh informasi tentang data hasil dari visiting proses marketing secara cepat dan tepat, serta data yang disimpan akan lebih terjamin serta laporan yang di inginkan dapat diperoleh lebih cepat dan dalam waktu yang lebih singkat.

\section{REFERENSI}

Fahrudin, A., Purnama, Eka, B., \& Berliana, R. K. (2015). Pembangunan Sistem Informasi Layanan Haji Berbasis Web Pada Kelompok Bimbingan Ibadah Haji. Speed, 9330(1), 63-71. https://doi.org/10.3112/speed.v3i1.884

Kotler Philip, dan G. A. (2014). Principles Of Marketing, Globa Edition.

Mega, P., \& Aviana, S. (2012). Penerapan pengendalian internal dalam sistem informasi akuntansi berbasis komputer, 1(4), 65-70.

Nazruddin Safaat. (2012). Pemrograman Aplikasi Mobile Smartphone dan Tablet PC Berbasis Android.

Stanton, W. J. (2013). Prinsip Pemasaran. Alih Bahasa oleh Buchari Alma.

Sutabri. (2012). Konsep Sistem Informasi.

Syahbana, A. (2010). Journal Speed - Sentra Penelitian Engineering dan Edukasi Volume 7 No 3 - 2015 - ijns.org. Jurnal Speed, 5(3), 7-12. https://doi.org/10.1109/MELCON.2000.88 0364

Wirawan. (2016). Evaluasi: Teori, Model, Standar, Aplikasi, dan Profesi (Edisi Revisi). Jakarta : Rajawali Pers. 